\title{
Investigation of Shielding Performance of Concretes Produced with Iron Fillings Using Betatron X-Ray Radiography
}

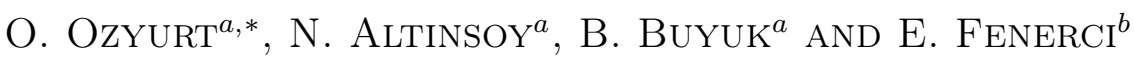 \\ ${ }^{a}$ Istanbul Technical University (ITU), Institute of Energy, Ayazaga Kampusu, 34469, Istanbul, Turkey \\ ${ }^{b}$ Nuh Beton INC., Buyukbakkalkoy Mh, Mezarlık Sk. No: 35 Maltepe/Istanbul, Turkey Institute of Energy \\ One of the most widely used structural materials in radiation shielding is concrete. Addition of metal par- \\ ticulates to concrete to enhance its density can be used for gamma and X-ray shielding purposes. In this study \\ radiation shielding performance of concrete containing different amounts of iron filling were evaluated using Be- \\ tatron X-ray radiation source. For this purpose concretes were produced by adding iron filling in the ratios of \\ $0 \%, 10 \%, 20 \%, 30 \%$ (in weight) to the cement. CIT/7.5 Betatron source which is a compact, circular electron \\ accelerator, generating directional X-ray beam, was used in this study. Experiments were performed by using \\ conventional radiography test. The results were compared with results for normal concrete. It was observed that \\ the film density differences between the iron filling and normal concrete are in the range of about 10-60\%.
}

DOI: 10.12693/APhysPolA.129.829

PACS/topics: 28.41.Qb

\section{Introduction}

There are three general rules for radiation protection: exposure time, distance, and shielding. In most cases, shielding is the main rule to be followed [1]. Although materials such as lead and iron are effective anti-ray shields, mechanical and economical considerations limit their usage to some special areas [2]. On the other hand concrete is one of the most important materials used for radiation shielding in facilities containing radioactive sources and radiation generating equipment. Radiation shielding concrete can be used to attenuate both neutron and photons. The photon interaction with the matter depends on the incoming photon energy and the density of the shielding material $[3,4]$. A good shielding material should have high absorption cross-section for radiation and at the same time irradiation effects on its mechanical properties should be small [5]. The concrete shielding properties may vary depending on the material components of the concrete. Aggregates are the largest constituent (about $70-80 \%$ of the total weight of normal concrete) $[3,6]$. The radiation shielding properties of concrete can be changed by adding different materials into concrete. Addition of metal particles to concrete to enhance its density can be used for gamma and X-ray shielding purposes. There are many different theoretical and experimental studies working on improvement of concrete properties to suit the shielding requirements by means of photon attenuation coefficient $[2,3,5-9]$. $\mathrm{X}$-rays have three principal uses as diagnostic, therapeutic and in non medical radiographic devices. Radiography is concerned with the production of radiographs, that is, the production of an image on photographic film

\footnotetext{
*corresponding author; e-mail: osmanozyurt87@gmail.com
}

by means of ionizing radiation such as X-rays and gamma rays. Industrial radiography has been developing steadily and as the manufacturers of equipment have broadened the range of their products, a large variety of possible techniques has become available, with a wide range of attainable flaw sensitivities [10]. Small-size betatrons are considered as source of X-ray radiation for industrial nondestructive testing. In this study radiation shielding performance of concretes containing iron filling in different rates were evaluated using a Betatron X-ray radiation source. Experiments were performed using conventional radiography test. The results were compared with those of normal concrete.

\section{Experimental details}

\subsection{Preparation of concrete blocks}

All concrete specimens $\left(15 \times 15 \times 15 \mathrm{~cm}^{3}\right)$ were prepared by R\&D Laboratory of Nuh Beton Inc. Concrete specimens were filled with different amounts of iron (Table I). Iron dust was supplied from Euroasia Mining INC. It includes $63.82 \% \mathrm{Fe}, 21.59 \% \mathrm{FeO}, 1.27 \% \mathrm{~S}$ and its density is $5.04 \mathrm{~g} / \mathrm{cm} 3$. Iron dust was kept for a while in a drying room before use. In addition, $0.125 \mathrm{~mm}$ mesh was used to make a homogeneous mixture of concrete.

TABLE I

The contents of the studied concrete blocks.

\begin{tabular}{c|c|c|c}
\hline \hline $\begin{array}{c}\text { Concrete } \\
\text { specimen }\end{array}$ & $\begin{array}{c}\mathrm{w} / \mathrm{c} \\
\text { ratio }\end{array}$ & $\begin{array}{c}\text { Iron ratio } \\
{[w t . \%]}\end{array}$ & $\begin{array}{c}\text { Density } \\
{\left[\mathrm{kg} / \mathrm{m}^{3}\right]}\end{array}$ \\
\hline S0 & 0.55 & 0 & 2.419 \\
S10 & 0.55 & 10 & 2.499 \\
S20 & 0.57 & 20 & 2.587 \\
S30 & 0.57 & 30 & 2.593
\end{tabular}




\subsection{Experimental setup}

Measurements were accomplished with the betatron radiography system at non destructive testing department of S\&Q MART INC. Technical specifications of the betatron X-ray source are given in Table II. Conventional radiography tests were performed at $7.4 \mathrm{MeV}$ by using Kodak Industrex MX125 films. The experimental setup is important in this kind of measurement. A general schematic diagram of experimental setup geometry is given in Fig. 1. Exposure parameters and experimental setup geometry are the same for all experiments. Exposure time was 5 minutes for each concrete. The betatron $\mathrm{X}$-ray source to film distance was $125 \mathrm{~cm}$ and the distance between the concrete samples and betatron varied between 80 and $110 \mathrm{~cm}$. All measurements were applied for three different concrete thicknesses $(15 \mathrm{~cm}, 30 \mathrm{~cm}$ and $45 \mathrm{~cm})$.

\section{TABLE II}

Technical specifications of betatron X-ray source.

\begin{tabular}{c|c}
\hline \hline X-ray output energy & 2 to $7.5 \mathrm{MeV}$ \\
Dose rate at $1 \mathrm{~m}$ in air & $5 \mathrm{R} /$ minute \\
Focal spot size & $0.3 \times 1.6 \mathrm{~mm}^{2}$ \\
Duty cycle at $20{ }^{\circ} \mathrm{C} / \mathrm{hr}$ & $75 \%$ \\
Radiation beam spread angle & 22 \\
Radiographic sensitivity & Typically $1 \%$
\end{tabular}

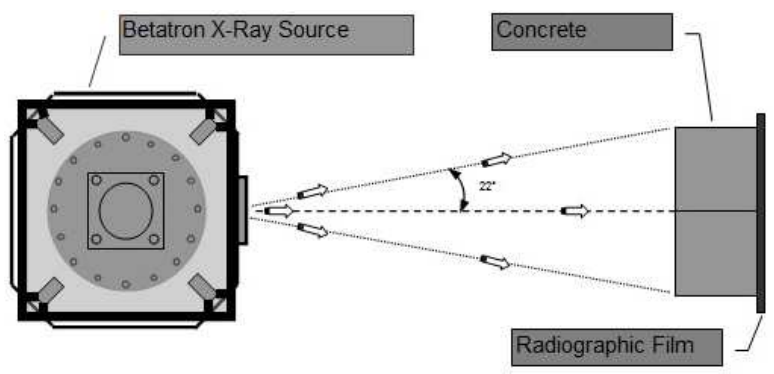

Fig. 1. The schematic diagram of experimental setup.

\subsection{Calibration of densitometer}

Xograph Digit X densitometer and Huatec film viewer were used for film density measurements. Before film density measurements, densitometer was calibrated with reference film at S\&Q Mart Calibration Laboratory. Densitometer readings were interpolated according to reference film values to achieve real values (Fig. 2). Each film was measured at 5 different points and the average values were taken into account.

\section{Results and discussion}

Density of the radiation incoming from the source is averaged as 4.7. Figure 3 shows the variation of film density with concrete thickness. Over 90\% correlations have been found for all concretes. As it can be seen from Fig. 3, film density decreases when the thickness

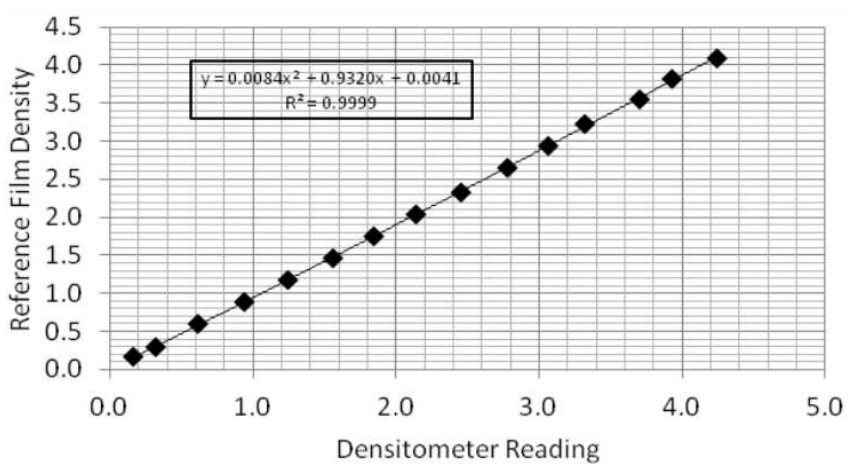

Fig. 2. Densitometer calibration curve.

of the concrete is increased. This is due to the intensity being attenuated when passing through the material. The density of the radiated film is proportional to the intensity of the radiation after passing through the sample. The thicker material means that more of the intensity is being attenuated. In this study, film densities of concretes with iron filling were compared with that of normal concrete. Figure 3 shows that film densities are decreasing with the increasing iron dust concentration in the concrete. Increase in the iron content (increase of the percentage of high atomic number elements) will result in a higher concrete density, thus will lead to a decrease in film density. It was observed that the differences in the values of film density are in the range of about $10-60 \%$. Maximum film density difference (60\%) was obtained for concrete incorporating $30 \mathrm{wt} \%$ of iron filling for concrete thickness of $30 \mathrm{~cm}$. It is getting harder to evaluate the radiographs for the thicker concretes due to the low film density.

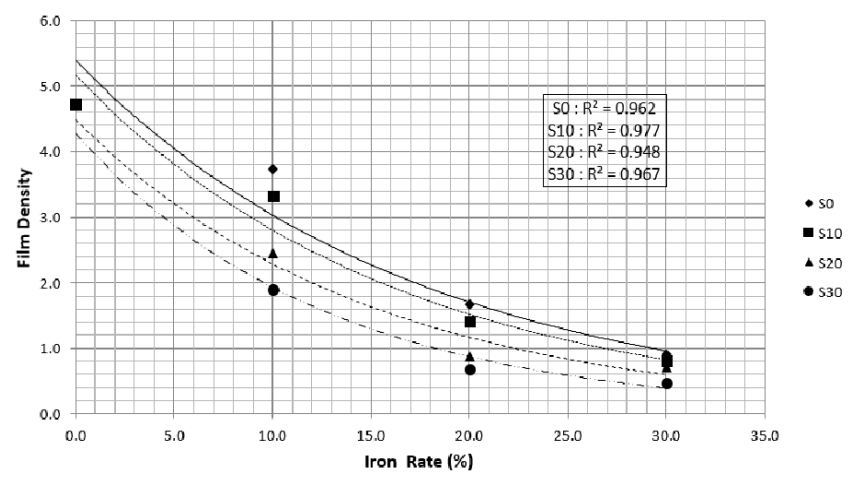

Fig. 3. Variation of film density with the thickness for S0, S10, S20, and S30 concrete blocks.

\section{Conclusions}

In this study X-ray shielding performance of concretes with iron filling has been studied using betatron X-ray source and radiography technique. According to the results, film densities decrease exponentially with the increasing iron dust concentration in the concrete (Fig. 3). Normal concrete and concretes with iron filling were compared by using film density difference. Maximum film 
density difference $(60 \%)$ was obtained for concrete incorporating $30 \mathrm{wt} . \%$ of iron filling for $30 \mathrm{~cm}$ concrete thickness. Exposure parameters used in this study can be applied to concretes with thickness of up to $30 \mathrm{~cm}$ to investigate the attenuation performance of concrete. This work confirms that the radiation shielding properties of concrete can be improved by using iron dust in concrete as the aggregate.

\section{Acknowledgments}

We would like to thank NUH BETON INC., S\&Q MART INC. and EURASIA MINING Co. Inc. for their special support.

\section{References}

[1] G. Eaves, Principles of Radiation Protection, Lliffe Books, London 1964.

[2] I. Akkurt, H. Akyıldırım, B. Mavi, S. Kılınçarslan, Ann. Nucl. Energy 37, 910 (2010).
[3] A.B. Azeez, K.S. Mohammed, A.M. Mustafa Al Bakri, K. Hussin, A.V. Sandu, R.A. Razak, $M a-$ terials 6, 4836 (2013).

[4] M.F. Kallan, Chen, M. Tian, S. Guo, Concrete Radiation Shielding, Longman Scientific and Technical, New York 1989.

[5] D. Demir, G. Keleş, Nucl. Instrum. Meth. B 245, 501 (2006).

[6] M.H. Kharita, Prog. Nucl. Energy 50, 33 (2008).

[7] A.B. Azeez, K.S. Mohammed, A.M. Mustafa Al Bakri, H.I. Hasan, O.A. Abdulkareem, Adv. Mater. Res. 92, 190 (2014).

[8] I. Akkurt, C.B. Basyigit, S. Kilicarslan, B. Mavi, A. Akkurt, Cement Concrete Comp. 28, 153 (2006).

[9] I.I. Bashter, Ann. Nucl. Energy 24, 1389 (1997).

[10] R. Halmshaw, Industrial Radiology, Chapman\&Hall, London, 1995. 